\title{
Users' Expectations on Restructuring OPACs through Social Network Applications
}

\author{
Nevzat Özel \\ Department of Information and Records Management \\ Ankara University \\ Ankara, Turkey \\ nozel@humanity.ankara.edu.tr
}

\author{
Tolga Çakmak \\ Department of Information Management \\ Hacettepe University \\ Ankara, Turkey \\ tcakmak@hacettepe.edu.tr
}

\begin{abstract}
The constant developments in web technologies have reconstructed the structure of most web-based applications and systems, causing web users to alter their behaviors/expectations. Playing an important role in the transference of information via multifarious technologies, libraries have been improving the structure and interface of their OPAC (Online Public Access Catalog) through utilizing various softwares so as to realize user's expectations. "The next generation OPACs" integrated with social network applications, maintain a more functional and user-centered structure. The aim of this paper is therefore to determine expectations of library users regarding the next generation OPACs which are considered to be one of the most important means of accessing the information resources in the libraries. To this end, 179 users (including students and academic staff) at Ankara University and Hacettepe University Libraries were applied a web-based survey, enabling them to reveal their expectations about the idea of reconstructing OPACs by social network applications and using library catalogs. It is the first user study regarding "adaptation of social network applications into OPACs" in Turkey.
\end{abstract}

Keywords: library catalogs; social networking; user studies.

\section{INTRODUCTION}

Web 2.0 technologies present communication media in sync with user participation to the web users. In this framework, individuals can contribute to the web contents and use them easily by means of social network applications. The users' interaction with the systems in these media leads them to have different expectations and needs.

Directly influenced by all the developments in technology, libraries are significant platforms that are apt to adopt these user-centered communication media. Libraries have a tendency to carry out their services in these media in accordance with the user expectations. The facileness of Web 2.0 technologies makes an important contribution to the idea of improving a new library environment, called as "Library 2.0".

The concept of "Library 2.0", initially expressed by Michael Casey, is defined as a user-centered model. It is supported by a constant evaluation process, providing user participation in producing physical and digital services [1] Library 2.0 can also be regarded as using Web 2.0 technologies associated with library resources and services. It helps the introduction of new services whilst increasing the interaction with the users and facilitating a more effective communication. According to Abram [2], Library 2.0 enables users to create next generation library web sites, databases, intranets, portals and OPACs.

Evaluated in terms of library services and user satisfaction, the social network environments function to make users manage the process of cataloging and classification individually, develop ontologies and folksonomies by means of keywords in web contents, obtain the electronic copies of books that users want via online shopping or publishers, prefer Wikis to reference services, use blogs, micro-blogs or chat rooms for informing each other about current developments or sharing ideas on certain subjects and take other users' evaluations into consideration instead of getting help from librarians concerning information resources and services [3].

The fact that most essential services traditionally offered by libraries can now be provided within a virtual environment, could initially be considered an impediment to the libraries. However, the integration of library services with social network applications is of great importance in terms of increasing effectiveness of these services.

Having a significant role in user retrieval of the information resources, OPACs used to give only bibliographic search and display options to the users a few years ago. But today, next generation OPACs which meet the expectations of users, find out the features of users and gather feedbacks with the effect of social network applications, are beginning to be created. The next generation OPACs facilitating the usage of these applications in the library catalogs include the features of "configurable relevance ranking", "subject tag maps or clouds", "clustering or faceting for filtering and expanding search results", "suggestions for additional searching based on authority headings", "indexing of data from several resources, such as circulation data and other catalogs or databases", "spelling corrections and user reviewing or tagging" [4]. The benefits of these features to libraries are as follows [5]:

Flexibility: The users can freely utilize library catalogs regardless of library's management systems in connection with specific data structures and administrative workflows.

Unification: Data from different resources can constitute one source of information for end users. 
Data enhancement: Data from library's management system is harvested with those from users and third-party resources including images of book covers, tables of contents, descriptions, and reviews.

Integration: It promotes the incorporation of new systems and standards into library's existing systems easily.

Step-by-step evolution: Libraries and users can add, change, and replace constituents of their systems gradually without influencing each other.

The next generation OPACs with these features, improve the value and functions of library catalogs so that they can meet the expectations of users on web, anticipate user participation/interaction, produce additional metadata information acquired from users, facilitate discovering information resources and become user friendly.

In this study, the needs for adaptation of social web applications to OPACs, adaptation methods and an assessment of using OPACs by the users of Ankara University Libraries and Hacettepe University Libraries in Turkey are carried out; their expectations with respect to the adaptation of social network applications to OPACs are reflected; and also some ideas regarding the improvement of library catalogs are introduced.

\section{LITERATURE REVIEW}

Web 2.0 technologies, also known as second generation web, has revived the subject of reconstructing OPACs, and questioning its current forms. Change in user expectations and insufficiency of OPACs in the process of determining the information resources that the users need are the main reasons for reconstructing.

Social network and online book stores (such as LibraryThing, del.icio.ous, Amazon.com) have been allowing users for a long time to create their own collections and share them with other users, express their expectations and rate these collections, and further get access to their own collections through creating their own tags. However, most library catalogs do not permit users to participate in these catalogs to this extent including such a social form [6].

Owing to OpenURL standard built into electronic information resources or licensed databases of library systems through search engines (e.g. Google Scholar), users can easily access services and resources provided by the library without using OPACs [7].

The Online Computer Library Center's (OCLC) 2005 research report, which has examined users' perceptions of library and information resources, affirms that $84 \%$ of users start to access information through search engines, and merely $1 \%$ of them prefer library catalogs. The report further indicates that users only apply library catalogs when they consider the possibility of finding the information resources they search are available in the library [8]. Regarding the evaluation of the bibliographic services in Bibliographic Services Task Force at the University of California Libraries [9], the report suggests that library catalogs are found defective in the process of finding, discovering and selecting information resources.
Echoing the results of the OCLC report, a study conducted at the University of Wisconsin Madison Libraries [10] have concluded that many researchers find using the information resources by conventional library tools as a frustrating and time consuming process. In his report, Breeding [11] highlights the complex search interfaces of library catalogs, attributing this issue to their not being sufficiently intuitive and consistent with well-established user interface conventions. He also points to their inability to rank results according to relevancy or interest, to address electronic content or to deliver online content to the user, further stating that they are too limited in scope, are tied to print materials, and they lack social network features to engage library users. All these cases reveal that users' expectations are different and it is required to develop the functions of OPACs.

Mainly, there are two approaches to the reconstruction of OPACs via social network applications: using open source software tools/technologies, and convincing library systems vendors to integrate these applications into OPACs [12]. Viewed in this context, open source softwares are Vufind, Blacklight, KOHA, SOPAC, OPALS, Evergreen and Scriblio (WPopac) and vendors softwares are Endeca, Primo, Encore, AquaBrowser, OCLC WorldCat Local, Prism, LibraryThing for Libraries, Polaris. The integration of these softwares into OPACs provides next generation catalogs with more powerful and appealing tools, in accordance with user expectations.

The user study in literature shows that users find the reconstruction of OPACs necessary. The 2009 OCLC report reveals users' expectations from library catalogs. Same study suggests that rating the library catalogs, giving expectations, guiding resources related to the subjects and seeing other users' list provide great benefits in the processes of users' discovering and selecting information resources [13].

In their study on OPACs and users, Chalon, Di Pretoro and Kohn [14] indicate that the incorporation of choices such as "commenting", "rating", "tagging", "book suggestion based on loans", "spelling suggestion", "faceted search", "SDI (Selected Dissemination of Information)" and "API (Application Program Interface)" into the library catalog is considerable in terms of enriching OPACs by users.

In another study by Tam, Cox and Bussy [15], a semistructured interview was conducted on 16 students studying at Sheffield University. The interview revealed students' expectations and offered an analysis of next generation OPACs. The study concluded that next generation OPACs provide an advantage in terms of time and convenience in the use of catalog.

A further study on social network applications in OPACs noted the expectations of 98 Library and Information Science students at Kent State University, listing the top five features which received the highest and lowest average rating for helpfulness. While the advanced search option, faceted navigation, sorting results options, simple search box, and enriched content received the highest rate for helpfulness; recently added items, user contributed content, word constellation, word clouds, and external links received the lowest [16]. 
As for Turkey, it can be argued that the concept of using social networking applications in OPACs is a relatively new subject. In a paper presented by Tonta [17], it is stated that online library catalogs in Turkey are insufficient in terms of accessing information about the contents of resources via social networking applications. In line with his observation, it could be stated that social networking applications in most of the OPACs in Turkey have not been implemented yet, and thus only search and display options have been offered to users. Despite the slow progress, new generation OPACs including social network structures have been recently put into effect at various library and information centers such as "Izmir Institute of Technology Library", "Özyeğin University Library", "Sabanc1 University Information Center", "TED Ankara College Library and Information Center". When analyzed in terms of user studies, the fact that there is no study examining the expectations and views of users about next generation OPACs in Turkey, augments the importance of this work and its contribution to the field.

\section{Methodology}

The focus groups of this study consist of Ankara and Hacettepe University Libraries' users who are graduate/undergraduate students and faculty staff. Findings of this study were obtained via web based survey that has been developed with the aim of determining and reflecting users' perspectives and expectations for the next generation OPACs.

The survey containing 10 questions was pre-tested with 6 participants. In May 2010, survey which was redesigned according to preliminary test results, were applied to 179 participants via e-mails, listserv messages and social networks. The questions in the study serve to find out user expectations about the adaptation of social network applications to OPACs, and are categorized in three major groups regarding content of information resources (5 questions), information retrieval (6 questions) and user interaction (7 questions).

The responses received from participants were evaluated by using SPSS (Statistical Package for the Social Sciences) program. All findings gathered in this study are based on the specified user expectations, so it cannot be generalized to every university in Turkey, and therein results should be interpreted cautiously.

Research questions of this study are presented below;

- How often do participants use OPACs for information seeking in electronic media?

- Which social network applications can be effectively used by participants in OPACs?

- According to user predictions, what are the effects of integration of social network applications with OPACs in terms of OPAC usage, information retrieval processes and decision making for determining related information resources processes?

- Do users have education requirements for next generation OPACs?

\section{FINDINGS}

In the first section of the study, the ways of accessing scientific information by participants and their expectations from OPACs were determined. It is seen that participants mostly ( $\mathrm{N}=115 / 64.2 \%$ ) prefer to use search engines such as Google, Yahoo! Search in the first rank, WWW resources $(\mathrm{N}=70 / 39.1 \%)$ in the second rank and online library catalogs in the third rank $(\mathrm{N}=50 / 27.9 \%)$. Related with this topic, OPACs usage frequencies are determined, and it is seen that most of the participants $(45.2 \%)$ use OPACs sometimes or several times during the term, $26.8 \%$ of the participants use OPACs on a regular basis - weekly or daily, $19 \%$ of participants use OPACs one or two times during the term and $\% 8.9$ of participants never use OPACs.

Sufficiency level of OPACs in terms of information retrieval is also measured through the participants' perspectives. Almost half of the participants (49.7\%) thought that OPACs are insufficient tools for information retrieval and although $30.7 \%$ of participants evaluated them as sufficient for information retrieval, $19.5 \%$ of them have expressed no idea about their sufficiency level.

\section{A. Contents of Information Resources}

In this part, the usefulness of the availability of contents of information resources in OPAC is measured using the likert scale. Table 1 shows findings that reflect user expectations about contents of information resources.

TABLE I. GENERAL OVERVIEW ON PROVIDING CONTENTS AND BRIEF
INFORMATION OF RESOURCES IN OPACS

\begin{tabular}{|l|l|l|l|l|l|l|}
\hline & & Useless & $\begin{array}{l}\text { Less } \\
\text { Useful }\end{array}$ & $\begin{array}{l}\text { Partially } \\
\text { Useful }\end{array}$ & Useful & $\begin{array}{l}\text { Very } \\
\text { Useful }\end{array}$ \\
\hline \multirow{2}{*}{ Summary } & $\mathrm{N}$ & 3 & 6 & 25 & 68 & 77 \\
\cline { 2 - 7 } & $\%$ & 1.7 & 3.4 & 14 & 38 & 43.0 \\
\hline \multirow{2}{*}{ Abstract } & $\mathrm{N}$ & 2 & 9 & 32 & 63 & 73 \\
\cline { 2 - 7 } & $\%$ & 1.1 & 5.1 & 17.9 & 35.2 & 40.8 \\
\hline \multirow{2}{*}{$\begin{array}{l}\text { Table of } \\
\text { contents }\end{array}$} & $\mathrm{N}$ & 2 & 6 & 18 & 58 & 95 \\
\cline { 2 - 7 } & $\%$ & 1.1 & 3.4 & 10.1 & 32.4 & 53.1 \\
\hline \multirow{2}{*}{$\begin{array}{l}\text { Cover } \\
\text { images }\end{array}$} & $\mathrm{N}$ & 13 & 41 & 67 & 33 & 25 \\
\cline { 2 - 7 } & $\%$ & 7.3 & 22.9 & 37.4 & 18.4 & 14.0 \\
\hline $\begin{array}{l}\text { Content } \\
\text { retrieval/ } \\
\text { preview } \\
\text { apps. }\end{array}$ & $\mathrm{N}$ & 4 & 14 & 21 & 72 & 68 \\
\cline { 2 - 7 } & $\%$ & 2.2 & 7.8 & 11.7 & 40.2 & 38.1 \\
\hline
\end{tabular}

Most of the participants (43\%) noted the appearance summary of information resources in OPACs as very useful. User expectations about appearances of abstract information in OPACs show that most of the participants (40.8\%) defined their expectations as very useful.

Another important feature of social network applications in OPACs is table of contents information in bibliographic records. More than half of the participants (53.1\%) agreed that this feature is very useful, while $32.4 \%$ of participants rated their expectations as useful. It is also seen that most of the 
participants $(37.4 \%)$ think cover images of information resources which provide identifiability are partially useful features, and while $22.9 \%$ of participants found this feature useless, $18.4 \%$ and $14 \%$ of the participants have stated that this feature is useful and very useful respectively.

Applications that offer content information, full texts and previews of information resources are other features of social network applications in OPACs. Our findings show that $40.2 \%$ of the participants have considered these functions as useful while $38.1 \%$ as very useful.

When we examine the appearance of content information of materials in OPACs; it is seen that table of content feature has the highest level of usefulness, and this is followed by summary information and abstract information with a rating of $43 \%$ and $40.8 \%$ respectively. Further, the participants' expectation about cover images of information resources in OPACs is a notable finding.

\section{B. Retrieval to Information Resources}

One of the properties of social network applications in OPACs is to provide sophisticated and effective information retrieval to library collection. In this respect, features like relevance ranks, directions for related materials, directions for related web pages, spelling algorithms, facet structures, etc. provide effectiveness and efficiency of information retrieval for information resources. In this study, six questions have been prepared for these features with the aim of exploring the ways in which these features contribute to information retrieval in OPACs based on the participants' expectations. Related findings are presented in Table 2.

TABLE II. GENERAL OVERVIEW ON PROVIDING ACCESS TO INFORMATION RESOURCES IN OPACS

\begin{tabular}{|c|c|c|c|c|c|c|}
\hline & & Useless & $\begin{array}{l}\text { Less } \\
\text { Useful }\end{array}$ & $\begin{array}{l}\text { Partially } \\
\text { Useful }\end{array}$ & Useful & $\begin{array}{l}\text { Very } \\
\text { Useful }\end{array}$ \\
\hline \multirow{2}{*}{$\begin{array}{l}\text { Relevance } \\
\text { ranks }\end{array}$} & $\mathrm{N}$ & 6 & 18 & 51 & 64 & 40 \\
\hline & $\%$ & 3.4 & 10.1 & 28.5 & 35.8 & 22.3 \\
\hline \multirow{2}{*}{$\begin{array}{l}\text { Links for } \\
\text { related } \\
\text { materials }\end{array}$} & $\mathrm{N}$ & 4 & 3 & 25 & 79 & 68 \\
\hline & $\%$ & 2.2 & 1.7 & 14.0 & 44.1 & 38.0 \\
\hline \multirow{2}{*}{$\begin{array}{l}\text { Links for } \\
\text { related web } \\
\text { pages }\end{array}$} & $\mathrm{N}$ & 12 & 23 & 53 & 63 & 28 \\
\hline & $\%$ & 6.7 & 12.8 & 29.6 & 35.2 & 15.6 \\
\hline \multirow{2}{*}{$\begin{array}{l}\text { Presentation } \\
\text { of editions \& } \\
\text { translations }\end{array}$} & $\mathrm{N}$ & 7 & 19 & 50 & 70 & 33 \\
\hline & $\%$ & 3.9 & 10.6 & 27.9 & 39.1 & 18.4 \\
\hline \multirow{2}{*}{$\begin{array}{l}\text { Spelling } \\
\text { algorithms }\end{array}$} & $\mathrm{N}$ & 4 & 13 & 32 & 67 & 63 \\
\hline & $\%$ & 2.2 & 7.3 & 17.9 & 37.4 & 35.2 \\
\hline \multirow{2}{*}{$\begin{array}{l}\text { Facet } \\
\text { structures }\end{array}$} & $\mathrm{N}$ & 5 & 10 & 33 & 76 & 55 \\
\hline & $\%$ & 2.8 & 5.6 & 18.4 & 42.5 & 30.7 \\
\hline
\end{tabular}

It is a significant retrieval factor that search mechanisms of OPACs provide fast and required results. Therefore, relevance ranks have an important role in retrieving search results in terms of effectiveness. In our study, most of the participants have expressed that their expectations about the implementation of relevance ranks in OPACs' search mechanisms are useful.

It is a vital function for users that viewing other related materials in OPACs accords with retrieving bibliographic information of materials. Findings also explore that most of the participants regards this feature as useful and very useful respectively (44.1\% and 38\%).

Appearance of links to other related web pages are also important for users in OPACs and findings show that while most of the participants $(35.2 \%)$ think that this feature is useful, only $6.7 \%$ have rated this feature as useless.

Participants' expectations about the appearance of translations and other editions of information resources in OPACs' records and findings indicate that most of the participants $(39.1 \%)$ have viewed this feature as useful, while only $3.9 \%$ found it useless.

Semantic structures have gained importance in new generation OPACs in order to provide effective retrieval to information resources. The aim of these forms is to convert incorrect search queries into the correct one through spelling algorithms with notifications such as "Did you mean this?" In this study, findings show most of the participants have found these forms very useful and useful $(37.4 \%$ and $35.2 \%$ respectively), whereas $9.5 \%$ have expressed that these forms are useless and less useful.

Facet structures are another topic in this study and findings show most of the participants $(42.5 \%)$ are of the opinion that the appearance of these forms is useful.

In this study, findings about providing retrieval to information resources via OPACs show that the applications, which offer links to related materials, have a higher level of usefulness than others in this category. The participants have also indicated that spelling algorithms and facet structures are also important functions of effective information retrieval.

\section{User Interaction}

Usage of social network applications in OPACs is important for bringing new properties based on user interaction with OPACs. Users can add tags and comments onto information resources or create tag clouds, read others' comments, notify circulation data of resources and utilize from RSS feeds and email notifications with the user interaction function of social OPACs. This part of the study, engages with the user evaluations about the properties, providing user interaction in OPACs (see Table 3).

One of the most important features of social network applications for users is tagging and tag clouds. With this feature users can add their own tags to records and create their own retrieval path for the materials by helping existing retrieval paths. Findings about this feature show that most of the participants $(36.9 \%)$ think that appearance of this feature in OPACs is useful. 
TABLE III. GENERAL OVERVIEW ON PROVIDING USER INTERACTION VIA OPACS

\begin{tabular}{|c|c|c|c|c|c|c|}
\hline & & Useless & $\begin{array}{l}\text { Less } \\
\text { Useful }\end{array}$ & $\begin{array}{l}\text { Partially } \\
\text { Useful }\end{array}$ & Useful & $\begin{array}{l}\text { Very } \\
\text { Useful }\end{array}$ \\
\hline \multirow{2}{*}{$\begin{array}{l}\text { Tag clouds } \\
\& \text { tagging }\end{array}$} & $\mathrm{N}$ & 6 & 22 & 56 & 66 & 29 \\
\hline & $\%$ & 3.4 & 12.3 & 31.3 & 36.9 & 16.2 \\
\hline \multirow{2}{*}{ Rating apps. } & $\mathrm{N}$ & 19 & 43 & 61 & 39 & 17 \\
\hline & $\%$ & 10.6 & 24.0 & 34.1 & 21.8 & 9.5 \\
\hline \multirow{2}{*}{$\begin{array}{l}\text { Circulation } \\
\text { statistics }\end{array}$} & $\mathrm{N}$ & 26 & 47 & 60 & 32 & 14 \\
\hline & $\%$ & 14.5 & 26.3 & 33.5 & 17.9 & 7.8 \\
\hline \multirow{2}{*}{$\begin{array}{l}\text { Related \& } \\
\text { circulated } \\
\text { materials } \\
\text { information }\end{array}$} & $\mathrm{N}$ & 21 & 34 & 61 & 46 & 17 \\
\hline & $\%$ & 11.7 & 19.0 & 34.1 & 25.7 & 9.5 \\
\hline \multirow{2}{*}{$\begin{array}{l}\text { Comment } \\
\text { apps. }\end{array}$} & $\mathrm{N}$ & 6 & 20 & 45 & 70 & 38 \\
\hline & $\%$ & 3.4 & 11.2 & 25.1 & 39.1 & 21.2 \\
\hline \multirow{2}{*}{$\begin{array}{l}\text { Personalized } \\
\text { collection }\end{array}$} & $\mathrm{N}$ & 5 & 18 & 46 & 75 & 35 \\
\hline & $\%$ & 2.8 & 10.1 & 25.7 & 41.9 & 19.6 \\
\hline \multirow{2}{*}{$\begin{array}{l}\text { RSS feeds } \\
\& \text { e-mail } \\
\text { notifications }\end{array}$} & $\mathrm{N}$ & 6 & 19 & 41 & 69 & 44 \\
\hline & $\%$ & 3.4 & 10.6 & 22.9 & 38.5 & 24.6 \\
\hline
\end{tabular}

While $34.1 \%$ of the participants have described their expectations about rating applications as partially useful, only $9.5 \%$ of the participants noted their expectations as very useful.

Other components for building OPACs with social network applications that provide user interaction are usage and circulation statistics of information resources. Most of the participants $(33.5 \%)$ have marked their expectations as partially useful, $26.3 \%$ of them considered the appearance of this application in OPACs as less useful, and only $7.8 \%$ of them found their expectations as very useful.

In connection with the previous question, the appearance of the information about related and circulated materials in OPACs has also been directed to the participants. Most of the participants $(34.1 \%)$ have revealed the appearance of this feature as partially useful, $25.7 \%$ of them specified this application as useful, and only $9.5 \%$ of the participants described their expectations about the application as very useful.

Findings about the comment applications, which provide direct user contribution to OPACs, show that $39.1 \%$ of the participants have defined this application as useful, while $3.4 \%$ as useless.

Adaptation of social network applications to OPACs also supplies personalization properties for users. In this context, they can create their own virtual sub-collections. Most of the participants $(41.9 \%)$ in our study have evaluated this feature as useful.

RSS feeds and e-mail notifications are other components for providing user interaction in OPACs via social network applications. By means of these features, users are informed about newcomers and innovations of the library as well as its collection. Our findings show that most of the participants
$(38.5 \%)$ have defined their expectations for this feature as useful.

Upon an examination of some of the findings obtained in this part of the study, it could be stated that the user interaction features of OPACs are found useful at low rates, whilst RSS feeds and e-mail notifications, Personal Collections, Commenting, Tagging and tag cloud features in OPACs are evaluated as useful by the participants.

\section{Effects of Social Network Applications for OPACs}

In this part, findings about which social network applications have effect/s on OPACs and how social network applications affect OPACs are shown in Table 4.

TABLE IV. USER NEEDS AND EXPECTATIONS FOR THE ADAPTATION OF SOCIAL NETWORK APPLICATIONS TO OPACS

\begin{tabular}{|l|l|l|l|l|}
\hline \multicolumn{2}{|l|}{ Expectations } & Disagree & Neutural & Agree \\
\hline \multirow{2}{*}{$\begin{array}{l}\text { Finding more materials in a } \\
\text { short time }\end{array}$} & $\mathrm{N}$ & 9 & 32 & 138 \\
\cline { 2 - 5 } & $\%$ & 5.0 & 17.9 & 77.1 \\
\hline \multirow{2}{*}{$\begin{array}{l}\text { Effective decision making for } \\
\text { determining materials }\end{array}$} & $\mathrm{N}$ & 11 & 31 & 137 \\
\cline { 2 - 5 } & $\%$ & 6.1 & 17.3 & 76.5 \\
\hline $\begin{array}{l}\text { More effective and greater } \\
\text { usage of materials }\end{array}$ & $\mathrm{N}$ & 11 & 32 & 136 \\
\cline { 2 - 5 } & $\%$ & 6.1 & 17.9 & 76.0 \\
\hline $\begin{array}{l}\text { More effective and greater } \\
\text { usage of OPACs }\end{array}$ & $\mathrm{N}$ & 8 & 24 & 147 \\
\cline { 2 - 5 } & $\%$ & 4.5 & 13.4 & 82.1 \\
\hline $\begin{array}{l}\text { Education need for usage } \\
\text { social network applications for } \\
\text { access to materials }\end{array}$ & $\mathrm{N}$ & 14 & 38 & 127 \\
\cline { 2 - 5 } & $\%$ & 7.8 & 21.2 & 70.9 \\
\hline
\end{tabular}

As is seen in Table $4,77.1 \%$ of the participants think that the adaptation of social network applications to OPACs could provide access to more information resources in a shorter time, $76.5 \%$ of the participants believe that OPACs with their social forms provide easy decision making for determining required information resources. While $76 \%$ of the participants are of the opinion that building social network structures in OPACs makes information resources more useful and efficient, $82.1 \%$ of the participants have revealed that social network applications increase usage rates and effectiveness of OPACs.

Another important finding of this study unearths the educational needs of the participants. Findings show that $70.9 \%$ of the participants have educational requirements which can be met by libraries via the usage of social network applications to information retrieval.

\section{CONCLUSION}

This study concludes that the preference of OPACs is not high in the process of users' access to scientific information electronically. OPACs are used for accessing information resources, but they are found insufficient by users with their existing structure.

Selections including the choices of "summary", "abstract", "table of contents" and "preview" related to the contents of information resources in OPACs; "relevance ranking" to 
facilitate access to information resources; "guiding users to the other related information resources and web sites"; giving links to other editions and translations"; "spelling algorithms" and "facet structures" are found considerably useful. The selections of "tagging/ tag clouds"; "comment applications"; "individual virtual collections development"; RSS feeds and email notifications" are also found very beneficial in terms of user interaction.

As the users have stated, reconstructing OPACs through social network applications enables them to access information resources in a short time, make a decision in the process of determining the required information resources, and use OPACs efficiently and effectively. Users feel the need of library education concerning social network applications included in next generation OPACs.

The conclusions obtained from this study are parallel to the report prepared by the OCLC in 2009 and the other related studies in the literature, revealing that Turkish users want to benefit from social network applications in OPACs.

Next generation OPACs including social network applications make it possible for users to give the opportunity to participate in discussions, share their comments and interact with other users. Consequently, the integration of current OPACs into social network applications by libraries using commercial or open resource software and raising awareness via library education enables OPACs to be more functional and user-centered. More importantly, they encourage users to benefit frequently from OPACs for their information needs.

\section{ACKNOWLEDGMENT}

We thank Professor Yaşar Tonta of Hacettepe University and Rabia Tekin Özel for helpful comments.

\section{REFERENCES}

[1] M. Casey and L. C. Savastinuk, "Library 2.0: Service for the nextgeneration library," Library Journal, vol. 131, no. 14, pp. 40-42, Sept. 2006 .

[2] S. Abram, Web 2.0, Library 2.0 and Librarian 2.0: preparing for the 2.0 world, Online Information Proceedings, pp. 6-8, 2007. http://2009.online-information.co.uk/files/freedownloads.newlink1.108 0622103251.pdf.

[3] Y. Tonta, "Digital natives, social networks and the future of libraries [Dijital yerliler, sosyal ağlar ve kütüphanelerin geleceği]”, Türk Kütüphaneciliği, vol. 23, no. 4, pp. 742-768, Dec. 2009.

[4] K. Wilson, "OPAC 2.0: Next generation online library catalogues ride the Web 2.0 wave!," Online Currents, vol. 21, no. 10, pp. 406-413, 2007.

[5] T. Sadeh, "User-centric solutions for scholarly research in the library," Liber Quarterly, vol. 17, no. 3/4, 2007.

[6] J. Wenzler, LibraryThing and the library catalog: Adding collective intelligence to the OPAC, 2007. http://online.sfsu.edu/ jwenzler/ research/LTFL.pdf.

[7] K. Coyle, "The library catalog in a 2.0 world," Journal of Academic Librarianship, vol. 33, no. 2, pp. 289-291, March 2007.

[8] OCLC, Perceptions of Libraries and Information Resources. Dublin, Ohio: OCLC Online Computer Library Center, 2005.

[9] Bibliographic Services Task Force, University of California Libraries, Rethinking how we provide bibliographic services for the University of California, 2005. http://libraries.universityofcalifornia.edu/sopag/BSTF/ Final.pdf.

[10] University of Wisconsin-Madison Libraries, Resource discovery exploratory task force final report, 2008. http://staff.library.wisc.edu/ rdetf/RDETF-final-report.pdf.

[11] M. Breeding, "Next-generation library catalogs," Library Technology Reports, vol. 43, no. 4, July/Aug. 2007.

[12] K. Wallis, "The next generation online public access catalog in academic libraries," Open and Libraries Class Journal, vol. 1, no. 2, Fall 2009.

[13] OCLC, Online Catalogs: What Users and Librarians Want. Dublin, Ohio: OCLC Online Computer Library Center, 2009.

[14] P. Chalon, E. Di Pretoro and L. Kohn, OPAC 2.0: Opportunities, developments and analysis, 2008. http://www.terkko.helsinki.fi/bmf/ EAHILpapers/Patrice_Chalon_paper.pdf.

[15] W. Tam, A. M. Cox and A. Bussy, "Student user preferences for features of next-generation OPACs: A case study of University of Sheffield international students," Program, vol. 43, no. 4, pp. 349-374, 2009.

[16] A. Salaba and Y. Zhang, User perspectives on NextGen catalog features, 2009. http://www.asis.org/Conferences/AM09/posters/72.pdf.

[17] Y. Tonta, Kütüphaneler sanal güzergâhlara mı dönüşüyor? [Are libraries becoming virtual destinations?], I.Uluslararası Bilgi Hizmetleri Sempozyumu, 2006. http://yunus.hacettepe.edu.tr/ tonta/yayinlar/tontaistanbul-mayis-2006-bildiri.pdf. 